\title{
TRANSVERSE FRACTURE THROUGH THE BODY OF THE AXIS
}

\author{
I. JAKIM, M. B. E. SWEET \\ From Hillbrow Hospital and the University of the Witwatersrand, Johannesburg
}

\begin{abstract}
We report a case of transverse fracture through the body of the axis. This fracture was unstable, had been produced by extension forces and was managed conservatively. The classification of such fractures is discussed.
\end{abstract}

The cervico-cranium (occiput, atlas and axis) has a distinctive functional anatomy, which is clearly different from that of the lower cervical spine (Penning 1968; Harris 1978; Jeffreys 1980). In injuries to the C1-C2 complex, force is generally applied via the base of the skull. The remainder of the cervical spine may be injured by forces which are applied either directly to the affected vertebrae or indirectly through a lever arm of several adjacent segments (White and Punjabi 1978).

We describe a patient who sustained a previously unreported transverse fracture through the body of the axis, as a result of an extension injury. We are able to postulate the precise mechanism of the injury.

\section{CASE REPORT}

A 24-year-old male pedestrian was struck by a car. $\mathrm{He}$ had no loss of consciousness and was admitted to a peripheral hospital with severe pain in the upper neck and marked guarding of any head movement. There were abrasions over his forehead and a contusionhaematoma over the upper third of his nose.

On examination, there was marked anterior and posterior tenderness over the upper segments of his neck, but no posterior bogginess and no neurological deficit. Radiographs of the cervical spine revealed a transverse fracture through the $\mathrm{C} 2$ vertebra with no displacement, but a marked degree of anterior soft tissue swelling (Fig. 1).

I. Jakim, MD, Consultant Orthopaedic Surgeon and Head of Department

Department of Orthopaedic Surgery, Hillbrow Hospital and University of the Witwatersrand Medical School, York Road, Parktown, Johannesburg 2193, Republic of South Africa.

M. B. E. Sweet, MB, ChB, PhD(Med), Reader in Experimental Orthopaedics

University of the Witwatersrand Medical School, York Road, Parktown, Johannesburg 2193, Republic of South Africa.

Correspondence should be sent to Professor M. B. E. Sweet.

(C) 1988 British Editorial Society of Bone and Joint Surgery

$0301-620 \mathrm{X} / 88 / 5150 \$ 2.00$

J Bone Joint Surg [Br] 1988;70-B:728-9.
Traction through Crutchfield skull tongs, applied with a bias to extension, resulted in posterior displacement of the fracture but no deterioration in neurological status (Fig. 2). Two weeks later the patient was transferred for consultation and further management. He refused any alternative treatment and traction was continued for six weeks. Flexion and extension radiographs, tomography and xerography then revealed that the fracture was stable and had united with posterior displacement (Fig. 3). The patient was discharged in a Somi brace for six weeks.

At a two-year follow-up visit no further displacement was noted and no neurological deficit had developed.

\section{DISCUSSION}

The transverse fracture through the body of the axis was clearly an unstable extension-type injury: the patient had a contusion on his forehead and the fracture was displaced by traction in extension. Maki (1985) described a transverse fracture through the body of the axis, which he attributed to a flexion-distraction injury similar to a Chance fracture in the thoracolumbar spine. In Maki's case the fracture line ran below the level of the superior articular facets, leaving the caudal part of the body of the axis attached to the posterior elements. The cranial segment consisted of a small part of the body together with the dens, thus resembling a Type III fracture in the classification of Anderson and D'Alonzo (1974). By contrast the fracture line in our case passed horizontally through the body leaving the posterior elements attached to the upper half of the body.

Gehweiler, Osborne and Becker (1980) classified fractures of the dens as either "high" or "low", corresponding to Anderson and D'Alonzo Type II and III respectively, but in their "low" dens fracture the ring is disrupted (Harris et al. 1984), as happened in Maki's case. The fracture in our case corresponded to neither of these categories in that the ring remained intact.

Another type of fracture of the body of the axis, 


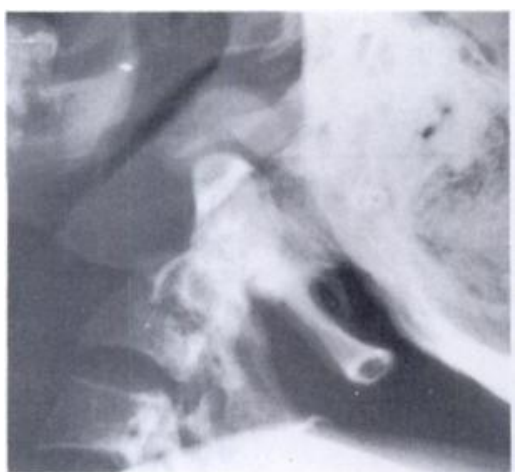

Fig. 1

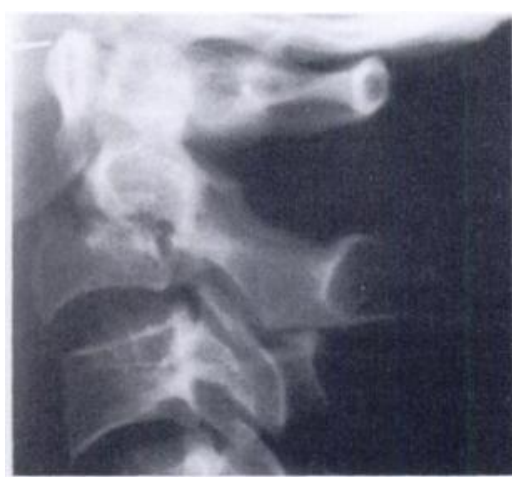

Fig. 2

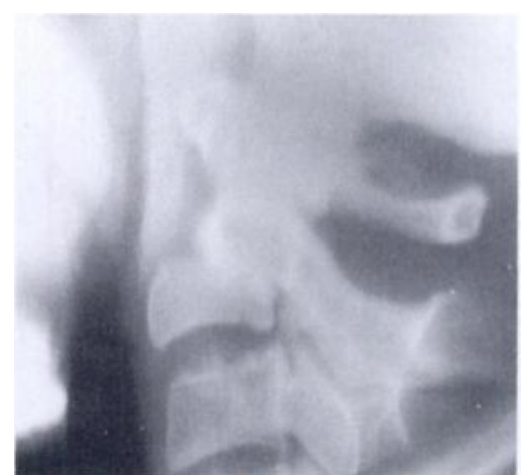

Fig. 3

Figure 1 - Lateral radiograph showing the undisplaced transverse fracture through the body of the axis and considerable anterior swelling of soft tissues. Figure 2 - Posterior displacement of the fracture in traction with a bias to extension. Figure 3 - Lateral tomogram confirming the displacement of the healed fracture.

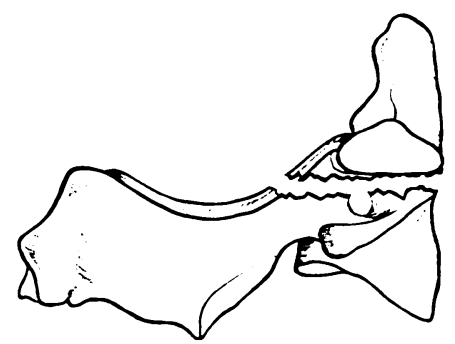

Fig. 4a

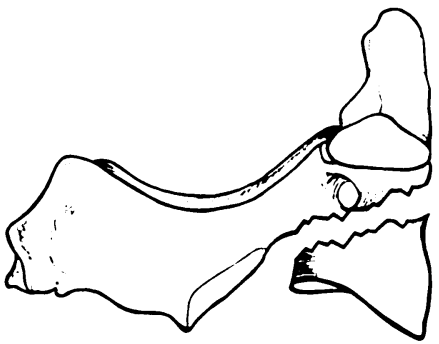

Fig. 4b

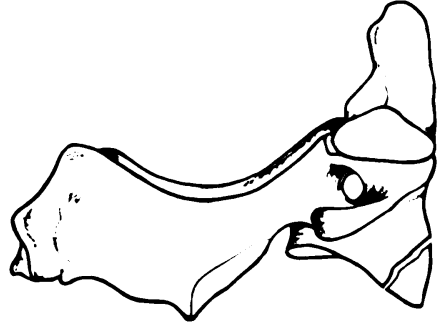

Fig. 4c

Diagrams to show: a) Anderson and D'Alonzo Type III fracture, b) true transverse fracture of the body of the axis with an intact ring. and c) a tear-drop fracture.

produced by extension forces, is the tear-drop fracture. Unlike the fracture we have described, this is considered to be stable and responds well to conservative treatment in a collar (Jeffreys 1980).

Fractures of the dens and of the neural arch of the axis have both been classified (Anderson and D'Alonzo 1974; Levine and Edwards 1986). We suggest that fractures of the body of the axis be classified as follows (Fig. 4):

a) the Anderson and D'Alonzo Type III fracture with disruption of the ring, which may be caused by a variety of mechanisms (Harris, Edeiken-Monroe and Kopaniky 1986)

b) a true transverse fracture without disruption of the ring, which is unstable and caused by an extension force c) the tear-drop fracture of the axis, also caused by extension, which is stable.

This work was supported by the South African Medical Research Council.

No benefits in any form have been received or will be received from a commercial party related directly or indirectly to the subject of this article.

\section{REFERENCES}

Anderson LD, D'Alonzo RT. Fractures of the odontoid process of the axis. J Bone Joint Surg [Am] 1974;56-A :1663-74.

Gehweiler JA Jr, Osbome RL Jr, Becker RF. The radiology of vertebral trauma. Philadelphia, etc: WB Saunders Co, 1980.

Harris JH Jr. The radiology of acute cervical spine trauma. Baltimore: Williams \& Wilkins Co, 1978:9.

Harris JH Jr, Burke JT, Ray RD, Nichols-Hostetter S, Lester RG. Low (Type III) odontoid fracture: a new radiologic sign. Radiology 1984:153:353-6.

Harris JH Jr, Edeiken-Monroe B, Kopaniky DR. A practical classification of acute cervical spine injuries. Orthop Clin North Am 1986:17:15-30.
Jefireys E. With a contribution by McSweeney T. Disorders of the cervical spine. London: Butterworths, 1980.

Levine AM, Edwards CC. Treatment of injuries in the $\mathrm{C} 1-\mathrm{C} 2$ complex. Orthop Clin North Am 1986;17:31-44.

Penning L. Functional pathology of the cervical spine. Radiographic studies of function and dysfunction in congenital disorders cervical spondylosis and injuries. Amsterdam, etc: Excerpta Medica Foundation, 1968.

Maki NJ. A transverse fracture through the body of the axis: a case report. Spine 1985;10:857-9.

White AA III, Punjabi MM. Clinical biomechanics of the spine. Philadelphia, etc: JB Lippincott Co, 1978. 